\title{
Student Responses to Small Group Discussion Learning Methods and Their Improvements
}

\author{
Asrinaldi ${ }^{1}$, Tamrin ${ }^{2}$ \\ \{ asrinaldi@soc.unand.ac.id ${ }^{1}$ \} \\ ${ }^{1,2}$ Faculty of Social and Political Science, Universitas Andalas, Padang, Indonesia
}

\begin{abstract}
The Small Group Discussion Method is one of the methods used to improve the achievement of learning competency outcomes for students through small group discussions on predetermined topics. In reality, the use of this method has not been fully able to improve the value of students taking courses such as the Political Science Methodology. This research was conducted on 67 subject participants by observing their behavior in small group discussions in discussing material provided for 10 weeks. Discussions were conducted with 15 groups assigned to discuss the material given to them. In addition, to find out student responses, then at the end of the lecture also distributed questionnaires. The results of this study found that there were still students who were not accustomed to expressing their opinions in front of many people. In the discussion process that took place it turned out that students were still dominating the group discussions conducted because besides being familiar with this method, they also had better mastery of the discussion material from various sources. Therefore this method needs to require students who are also looking for other sources related to the material being.
\end{abstract}

Keywords: Responses, Students, Discussions and SCL

\section{Introduction}

The use of student-centered research methods (Student Center Learning, or SCL) does not always help learning participants understand the material taught easily. The implementation of SCL is very dependent on students as a center of learning. Certainly so students can take part in this SCL, then they must have the motivation within themselves to be able to achieve the expected competence. Because in learning using the SCL method, students are required to be able to show themselves in groups. This ability is related to how they discuss, actively argue, can criticize and analyze and find solutions related to the problem being discussed. This is in line with what Henson [1] explained, that SCL is a "model is teaching integrative thinking, based on existing models of creativity and synthesis. In this model, the student is put at the heart of a bigger learning process that includes instructors, specialists, and the public. " The problem is what about students who have no motivation, do not have the ability, and do not have the critical power as required in the SCL lecture.

SCL has many methods that can be used for student learning. But how to use this SCL method depends on the learning material that will be given by the lecturer while understanding how the character of the students being taught. Therefore it is not surprising that lecturers will choose the relevant SCL method. However, often the selection of this method is not in accordance with the character of students. In some cases, there are students who are also familiar with the direct learning received from their lecturers. As a result, this SCL has become a problem and a threat to them. This is why, when they are in high school (high school), they are 
accustomed to receiving lessons directly from the teacher so that it becomes a habit when they become students. They find it difficult to change behavior like this.

This study explains how student responses are related to the Small Group Discussion method, one of the methods in SCL that is often used in the lecture process. Unfortunately, from the use of this method, several problems have emerged from observations in this Political Science Methodology course. First, the discussion material made as a group report to be presented in class has not been in-depth in accordance with the concepts that have been taught; Second, those who make papers tend to be one or two dominant people in the group so that the others are only passive; Third, the tendency in-class discussion is also the same because it makes only one or two people so that those who understand the discussion material are also those who write the report; Fourth, the class discussions that were attended by students lacked quality because most of the students only received and waited for information from the group presenting. Even though they have been given the same task to explore the topic and discuss together in front of the class.

\section{Literature Review}

Student-Centered Learning (SCL) is a learning method used by lecturers in higher education to get certain competencies in a course. This assumption departs from the tendency of individuals who are increasingly increasing a person's new knowledge, the more influence the attitudes and behavior that is getting more qualified. Many education experts agree that this SCL can provide new experiences for students in exploring the knowledge they learn [2]. Therefore it is not surprising, almost all lecturers in Indonesia choose to apply this SCL learning method because it can encourage students to become more active. This is in line with Figure 1 below which explains how the ideal of the lecturer-student relationship in the teaching-learning process in higher education.

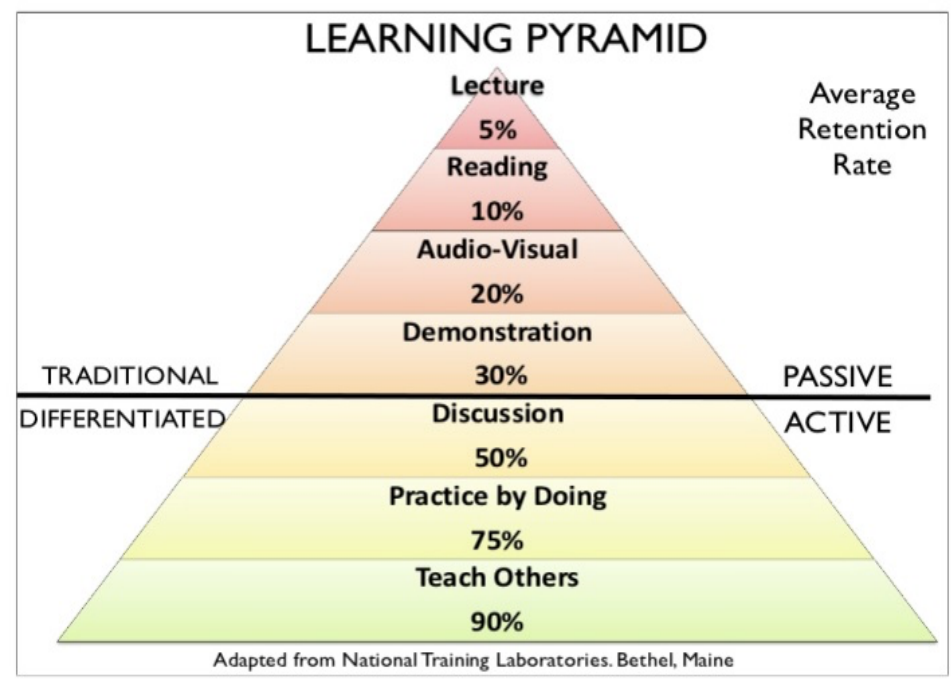

Fig.1. The learning pyramid [3] 
One of the SCL methods that is often used by lecturers in the Department of Political Science is Small Group Discussion (SGD). The SGD method is understood as a learning method that involves few people actively discussing finding answers or solutions related to the problem being discussed. So basically this SGD encourages each individual to talk and think related to what is said in the group. Simply put, Curzon [4] explains that SGD is related to who speaks based on joint exploration and evaluation of public ideas. Therefore in the implementation of this method, each student in the group has an initial knowledge of a problem and enriches their knowledge through the deepening that they do together. The small group discussion was guided by a chair chosen from the group.

Edward \& Mercer [5] emphasized that students who study in tertiary institutions should be actively involved in class to take advantage of their potential. In this way students will find out how they absorb knowledge while improving their knowledge. Although, in much literature, not all learning methods are suitable for all students being taught. In fact, every individual has limitations in understanding the subjects learned from the methods used. In other words, each person has a way of understanding the subject of his knowledge with different methods. Therefore, there is no specific formula that can uniform the level of absorption of students' knowledge related to the subject they are studying.

Of the several learning methods used, in general the process or stage of a person shapes his understanding following what is explained by Kolb [6]. According to Kolb, there are four stages that tend to occur in individuals in search of knowledge. This stage is also called the circle of learning through experience. The circle is the stages experienced by the teaching participants who internalize the value of the knowledge they get during learning. In a level the process can be seen from the following figure.

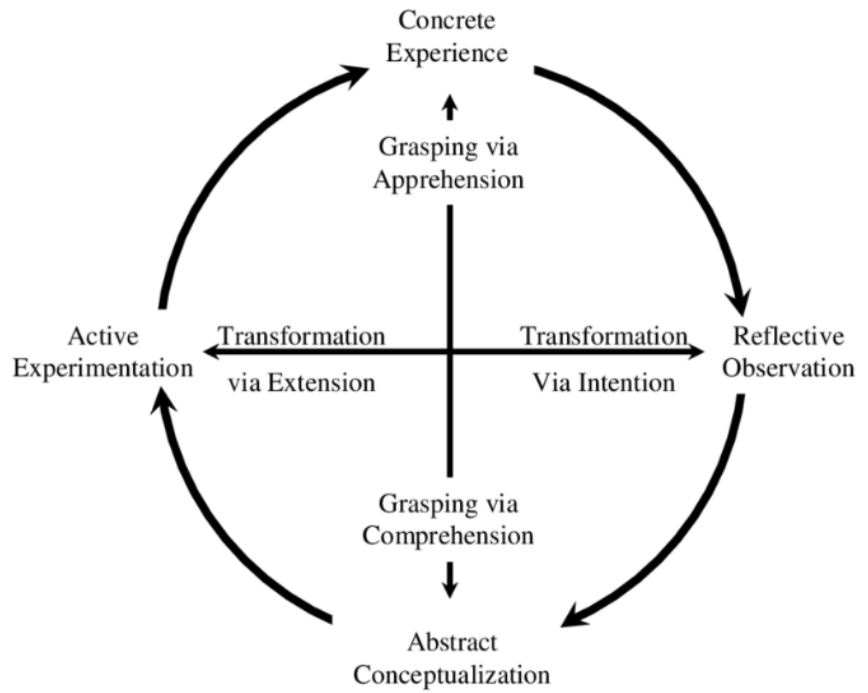

Fig. 2. Model of the Experiential Learning Process [6]

The competencies expected from the learning process clearly become the basis for a lecturer choosing what method is appropriate for their students. From Figure 2 above, it can be 
seen that each stage through which participants teach will help them understand the material taught in the construction of their way of thinking. Therefore, it is not easy for lecturers to uniform the abilities of teaching participants based on the above theoretical construction. Of course there are levels that must be passed at once achieved by students through the material being taught. One option is to prioritize aspects of the experience of teaching participants is the Small Group Discussion (SGD) method. For a lecturer to determine the method of delivering learning material, it is just as difficult as finding teaching material to be delivered, which can stimulate students' way of thinking related to the material being taught.

\section{Small group Discussion as a Learning}

Indeed there are many methods in learning this SCL. One that is often used by lecturers in the Department of Political Science is Small Group Discussion (SGD). The SGD method is understood as a learning method that involves few people actively discussing finding answers or solutions related to the problem being discussed. Basically, this SGD encourages each individual to talk and think related to what is discussed in the group. Simply put, Curzon [4] explains that SGD is related to who speaks based on joint exploration and evaluation of public ideas. Therefore in the implementation of this method, each student in the group has initial knowledge of a problem and participates in enriching their knowledge through the deepening that they have done together. The small group discussion was guided by a chair chosen from the group.

Even so, this SGD method also leaves a serious problem. Gall \& Gillet [7] explained that small discussions held in classroom learning do not encourage all students to be actively involved. Many students are silent and do not participate in discussions designed for them. Not to mention the anxiety and nervousness experienced by the teaching participants. As a result, lecturers are also reluctant to use this method to achieve the desired learning outcomes. Meanwhile, problems are often found noisy and uncontrolled classes that cause lecturers feel uncomfortable with the situation. Unfortunately, lecturers have not been able to maximize this method by helping students explain what they are discussing in accordance with the given topic. Generally lecturers are only observers and provide an assessment of the process. Of course this condition is not in line with the expected learning outcomes.

If the choice of SGD must indeed be carried out in class, the lecturer must prepare several steps so that learning outcomes through the use of this method can be realized. First, divide learning groups into peers who have the same abilities. This is intended so that motivation arises from students to engage in discussions that are held. Especially in the context of this group discussion which is important is the emergence of reciprocal influence principles. Second, group discussion is not just giving freedom for students to express their opinions or ideas. More than that, in group discussions that need to be instilled with participants is to speak based on the results of their reading based on textbooks, observe the environment around them by writing in their workbooks, and completing the tasks given to them. In this way, SGD will be effective in realizing the learning objectives.

\section{Method}

This study uses a descriptive quantitative approach through a survey of the perceptions of students taking Political Science Methodology courses in 2018/2019. Observations on the discussion process were carried out for 10 weeks by observing the SGD process. Steps to be taken (1) Students will be divided into 15 small groups. This is based on the consideration of the large number of students, which is 67 people. By dividing them into small groups, it will be 
easier to control the experiments that will be carried out; (2) Each group will be divided with special material, each of which is different to be discussed in their groups. The material is related to lecture material that they must understand through joint discussion. Students are asked to actively explore every concept and theory in the material being taught. At this stage the lecturer helps explain each material discussed by the group that is discussing it so that students have the same understanding to continue the discussion. (3) After students report the discussion in accordance with the material provided, then they are asked to develop this discussion in the case they explore from various sources. (4) Each group is asked to submit the results of their discussion into a report and present it in class discussion for comments from each group. Besides being an observer, the lecturer also participates in the class discussion to find out the students' responses related to the presentations delivered by each group. As an observer, the lecturer observes the dynamics of the class that is taking place by comparing the results of the small group discussions they did previously. Special attention is still given by looking at student responses in class discussions held. (5) After all groups have submitted the results of their class discussion, the lecturer is able to distribute questionnaires containing prepared questions related to the material they have received, the level of understanding, rhetorical and logical skills and experience, and knowledge gained during the discussion they participated in. This questionnaire was created using Google form and filled in online; (6) The results of the student responses are processed and analyzed to obtain relevant explanations to find solutions related to problems in the use of the Small Group Discussion Method.

\section{Result and Finding}

\section{Student Responses to Small Group Discussion (SGD)}

Small-Group Discussion is not a new method used in learning. Seeing from the method and its purpose, SGD is widely used, especially for teachers who want to know the responses and understanding of students related to the material they want to learn. SGD is part of the Student Center Learning (SCL) method, which is one of the ways used to realize the student competencies that are to be achieved. In fact, most students already know and are familiar with the SCL applied in the learning they are taking.

In addition, this questionnaire also asked about the students' habits related to the use of SGD in the learning activities they participated in. Moreover, most of them also already know the SCL method. As many as 84.6 percent of students are familiar with this method and only 15.4 percent are not familiar with this method. However, only 59.1 percent felt an increase in the knowledge they gained when following and using the SGD method. The following graphs successively illustrate student responses related to the questions above. 


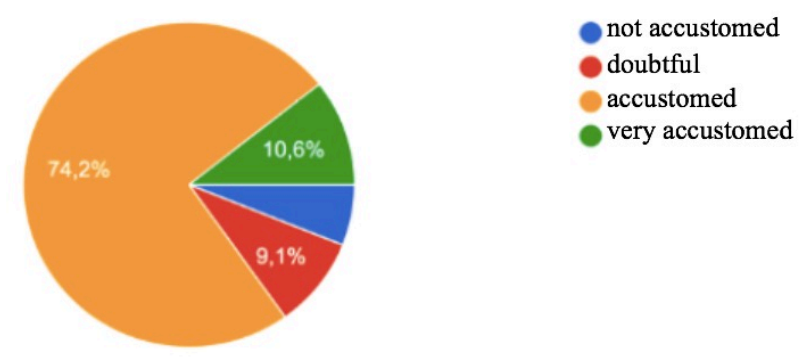

Fig. 3. The habits of students using SGD in learning

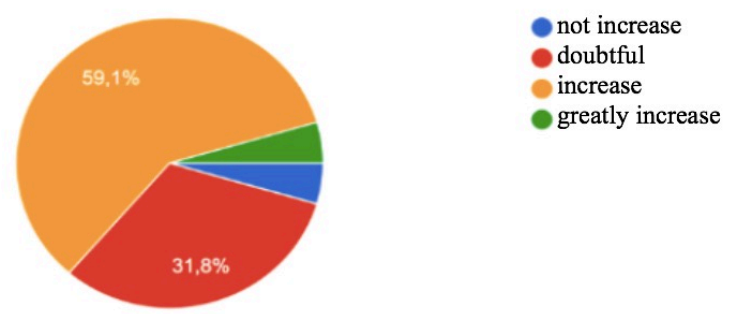

Fig.4. Increasing student knowledge using SGD

Although, lecturers have given assignments before SGD implementation in order to understand the material, but the fact is not all students prepare the material well. Quite a lot of them had difficulty following the material presented in SGD because they did not prepare it properly, which was 36.4 percent as shown in the following figure.
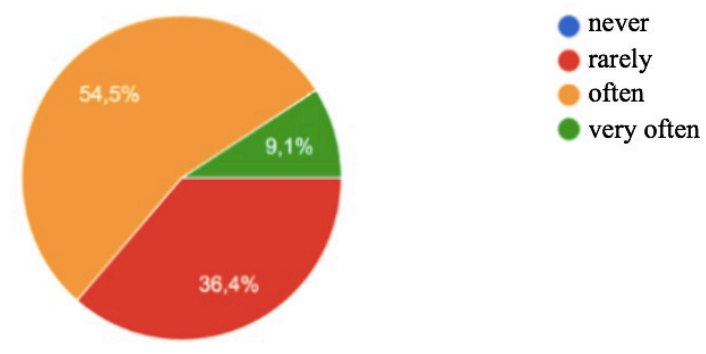

Fig.5. Making preparations before attending SGD

Of the several problems in the SGD there are many things that cause why SGD has not been optimally used as a learning method. Among these causes there are dominant factors 
conveyed by students such as their difficulty in understanding the material presented by the speaker in class discussions. In addition, there are also factors that are not the focus of the material presented by the speaker, especially the groups that present, causing them to have difficulty understanding the information provided. The following table can be seen the problems faced by SGD participants in class discussions.

Table 1. Fundamental issues faced by SGD participants

\begin{tabular}{lll}
\hline No & Problems & Percentage \\
\hline 1 & Difficulty understanding the material presented by the speaker & 36,4 \\
2 & Material discussion is not focused & 33,3 \\
3 & Cannot express opinions in front of the class & 13,6 \\
4 & Not familiar with group learning methods & 7,6 \\
5 & Others & 9,1 \\
\hline & $\mathrm{n}=66$
\end{tabular}

\section{Problems and Identification of Factors that Determine the Success of SGD}

Small-Group Discussion (SGD) as a learning method has advantages compared to other methods in the Student-Centered Learning (SCL) method. Among its strengths is encouraging students to be more creative in discussing subject matter through small group discussions. They will be actively involved in finding alternative comparisons in discussing subject matter that leads to the improvement of problem-solving skills by utilizing the critical thinking skills they have [8]. Even so, this method also has a number of weaknesses such as the dominance of discussions from students who have studied the discussion material from various sources before the discussion takes place. In addition, students who are not accustomed to speaking will not be able to express their thoughts in group and class discussions. As a result, these students will tend to be passive and unable to develop their ideas related to the material discussed. Though what is expected from the use of this method is the active participation of students and improve their critical thinking skills [9].

Another thing that was also found in this study was that there were still students who only listened to what the lecturer explained so they tended to be passive and did not participate in class. This condition is exacerbated by the style of lecturers who tend to dominate the learning process causing students to only be able to accept all lessons without going through a critical process. In the learning process in the classroom, there is indeed a classic method that lecturers rely on that the learning center is in themselves [10][11]. Students tend to be used as objects to receive "truth" from lecturers. This habit clearly impacts the courage of students to compare their opinions with those of lecturers.

Another important issue that needs attention is that not all students are accustomed to learning in a crowded atmosphere and take place in a process of debate. According to Garside [8] discussion and debate in groups have the advantage of training students to have the courage to express their opinions critically. Even students will look for more information related to the material commented on from various sources. This method clearly brings new knowledge to students. However, behind these advantages, there are also fundamental weaknesses, namely debates that sometimes do not focus on the problem being discussed. At least, from the results of this study as many as 7.6 percent of students who took this course did not focus on this SGD method. Although few in number, but this remains a concern, why students are not focused on this learning method.

Many scientists agree that the use of group discussion methods is very important to shape students' analytical and synthesis abilities and is useful for building their confidence. For 
example, Rahman et al. [12] explains "... discussion methods are more effective than didactic methods for stimulating thought, for personal social adjustment, and for changing attitudes, and are no worse than the lecture for effectively transmitting information." so the choice to implement SGD is still considered relevant to achieving that goal. Even so, students must also be taught in advance basic knowledge related to the discussions they will conduct, especially those who have never attended. But for those who have been active in campus organizations, discussing in small groups is something they usually do. This clearly benefits them when this method is applied in the lectures that are followed.

Likewise, the success of students attending SGD also depends on how they prepare themselves with the material provided. From observations, discussion in the group will take place well, if all participants in the group learn it first. Even good preparation does not only refer to the material provided by the lecturer, but also other relevant material to complement the main material provided. This is indeed a serious problem for students in using the SGD method because the material they use is still dependent on the lecturer. Though the material provided by the lecturer can be supplemented by students by searching for it from many sources. A lot of material is available in reference books and other online media that have not been well utilized. Therefore, to realize the purpose of using this method, it is indeed necessary to motivate students to prepare other materials independently.

According to Abdullah, Bakar \& Mahbob [13] understands learning material well, that is, looking for as much information as possible related to the assignment material charged is the key to success following this method. If this can be fulfilled by students, then the success of students achieving competencies is expected to be realized. However, from the field data, the low motivation of students to look for other information related to lecture material is still widely found. Therefore, another strategy is needed so that focused discussion in small groups can be carried out. During this time lecturers supporting courses indeed give freedom to students to add needed material. However, there are not many students who use this method so that group discussion cannot be carried out properly.

By looking at some of the problems experienced by students, the lecturer needs to give clear instructions on the implementation of SGD, especially encouraging them to use various sources of information in accordance with the material being taught. The use of learning resources is no longer limited to the available text books. Because the availability of information available on the internet is a new source that can enrich the discussion material discussed. The focus of the use of material from internet sources is not only on how to cite sources in the working paper, but also how to convey it to others. Because students, also find it difficult to answer the questions asked by participants in the discussion so that they need other sources to complete the answers. Therefore, students must master the source of knowledge and how to cite the source so that it will improve the quality of papers made and the quality of information delivery to the discussion participants.

\section{Conclusion}

This study explains the problems found in the use of the Small Group Discussion method in the learning process in Higher Education. In this study it was found that SGD was often used in the learning process and became a choice often made by lecturers among other studentcentered learning methods. However, SGD has fundamental weaknesses that need to be anticipated so that their use becomes effective. For example, SGD requires preconditions before implementation such as students must be familiar with SGD so they dare to express their opinions in public. For students to prepare other material to enrich the material provided by the 
lecturer. Usually, with additional material sought from other sources, students will have the courage to express their ideas in group discussions. In addition, the students' habit of participating in various informal discussions both in study groups and in extra-curricular organizations is very helpful in the implementation of this SGD. Their participation in discussion activities in extra-curricular organizations that were followed encouraged the emergence of motivation to convey their ideas in SGD. The results of this study have also explained that those who often join extracurricular organizations tend to become active in class when lecturers use this SGD. Therefore, lecturers need to know how the background of students who follow their lectures well before establishing this method. Moreover, not all students can get an understanding related to the material provided by using the SGD.

This research also confirms that lecturers who use the SGD method need to brainstorm before giving out material that will be discussed by students. Considering that not all students have enough knowledge to start a group discussion. Brainstorming activities started by lecturers can trigger a deeper discussion. Lecturers can start by asking key questions to be answered so students are triggered to think of the answers they will convey in the discussion. Another thing that also needs to be prepared by SGD participants is the references needed in the discussion, especially from internet sources. Students are given the freedom to use various references when SGD is implemented. Of course its use must be wise by reprocessing the learning material in the SGD that is implemented. Therefore, lecturers need to show how to use and cite sources from the internet. It is important to note that material from this internet source needs to be reprocessed into a reference to make it scientific.

\section{Acknowledgment}

Thank you to the Institute for Education Development and Quality Assurance (LP3M) which has provided the Education Development and Quality Assurance Research Scheme (PPMP) of Andalas University in 2019.

\section{Reference}

[1] Hesson, M., \& Shad, K.F., (2007), A Student- Centered Learning Model. American Journal of Applied Sciences. 4 (9), 628-636.

[2] Jacobs, G. M, Renandya, W. A., Power, M. (2016), simple, Powerful Strategies for Student Centered Learning, Singapore: Springer.

[3] Rosada, D. (2015). Student Center Learning. https://www.uinjkt.ac.id/id/student-centeredlearning-2/ <diakses 12/2/2018>.

[4] Curzon, L.B., (1990), Teaching in FE, 4th Ed. London: Cassell.

[5] Edwards, D and Mercer, N. (2013). Common Knowledge: The Development of Understanding in the Classroom. London: Routledge.

[6] Kolb, D. A. (1984). Experiential learning: Experience as the source of learning and development (Vol. 1). Englewood Cliffs, NJ: Prentice-Hall.

[7] Gall, M.D and \& Gillett, M. (1980), "The discussion method in classroom teaching", Theory Into Practice, 19 (2), 98-103, DOI: 10.1080/00405848009542881.

[8] Garside, C. (1996). "Look who's talking: A comparison of lecture and group discussion teaching strategies in developing critical thinking skills", Communication Education, 45 (3), 212-227, DOI: $10.1080 / 03634529609379050$.

[9] Rehner, J. (1994). Practical strategies for critical thinking. Boston, MA: Houghton M.

[10] Karmos, J. S., \& Karmos, A. H. (1987). Strategies for active involvement in problem-solving. In 
M. Heiman and J. Slomianko (Eds.), Thinking skills and instruction: Concepts and techniques. Washington, D.C.: National Education Association.

[11] Schunk, D. H. (1995). "Self efficacy and education and instruction", In Maddux (ed.), Self efficacy, adaptation and adjustment: theory, research and application. New York: Plenum Press. Pp. 281-303.

[12] Rahman, F., Khalil, J.K., Jumani, N.B., Ajmal, M., Malik, S. and Sharif, M. (2011). "Impact of Discussion Method and Student Performance, International Journal of Business and Social Science, 2(7):84-94.

[13] Abdullah, M.Y., Bakar, N.R.A, and Mahbob, M.H. (2012) Student's participation in classroom: What motivates them to speak up? Procedia - Social and Behavioral Sciences, 51: 516 -522 . 